\title{
Estigma e Ciberespaço: desafios da netnografia como metodologia para pesquisa de redes temáticas na blogosfera
}

Miguel Hexel Herrera; Ciências Sociais IFCH - UFRGS; h.miguel@ gmail.com Liliana Maria Passerino; Doutora pelo PPGIE - UFRGS; liliana@ cinted.ufrgs.br

Resumo: O estigma é uma situação (em muitos casos, permanente) presente na sociedade na qual o indivíduo é impossibilitado de ser aceito por seus pares. $\mathrm{O}$ objetivo de nossa pesquisa é utilizar a netnografia na blogosfera na busca de redes temáticas que nos permitam mapear e estabelecer critérios para análise sociabilidade em espaços virtuais estabelecidos entre pessoas com deficiência (neste caso visual) e familiares ou amigos. Em particular, pretendemos compreender como o cego utiliza-se dos blogs, quais suas dificuldades, como lida com seu estigma na rede, que barreiras físicas, sensoriais e tecnológicas defrontam esses indivíduos na busca pela sua inclusão social.

Palavras Chave: Estigma, netnografia, blogs, pessoas com deficiência

Stigma and Cyberspace: challenges of netnography as methodology for research of thematic networks in blogosphere.

Abstract: The stigma is a situation in many cases, permanent which individuals are unable to be accepted by their peers. The research aim is from netnography in Blogosphere for research thematic networks and to map and to establish criteria for sociability analysis in virtual environment used for disabled people (in this case visual) and family or friends. In particular, we want to understand how the blind use of blogs, what their difficulties, such as dealing with its stigma in the network, that physical barriers, sensory and technological facing these individuals to goal for social inclusion

Keywords: Stigma, netnography, blogs, disabled people

\section{Introdução}

\begin{abstract}
Alguns podem hesitar em tocar ou guiar o cego, enquanto que outros generalizam a deficiência de visão sob a forma de uma gestalt de incapacidade,(...) (Goffman, 1988, p. 15)
\end{abstract}

O estigma é uma situação (em muitos casos, permanente) presente na sociedade na qual o indivíduo é impossibilitado de ser aceito por seus pares. O objetivo de nossa pesquisa é utilizar a netnografia na blogosfera na busca de redes temáticas que nos permitam mapear e estabelecer critérios para análise sociabilidade em espaços virtuais estabelecidos entre pessoas com deficiência (neste caso visual) e familiares ou amigos. Em particular, pretendemos compreender como o cego utiliza-se dos blogs, quais suas dificuldades, como lida com seu estigma na rede, que barreiras físicas, sensoriais e tecnológicas defrontam esses indivíduos na busca pela sua inclusão social. A seguir, 
apresentamos uma análise dos desafios da Netnografia no estudo de redes temáticas instituídas na Blogosfera por cegos desde a ótica do estigma na visão de Goffman (1988).

\section{Estigma: suas implicações na construção de identidade social}

$\mathrm{Na}$ Antiguidade, estigmas eram marcas feitas com ferro e fogo em escravos, ladrões ou traidores, servindo de advertência para que não se travasse contato social com aquelas pessoas marcadas. Posteriormente, a Igreja adota o termo para evidenciar "marcas divinas" possuídas por indivíduos iluminados ou especiais. Nos dias de hoje utilizamos a palavra menos no sentido físico-religioso, e mais no sentido social, psicológico e moral, como destaca Goffman: "Há mais de uma década vem sendo apresentada uma quantidade razoável de trabalhos sobre estigma - a situação do indivíduo que está inabilitado para a aceitação social plena" (Goffman, 1988, p.7).

Para Goffman (1988) estigma é um rótulo que uma pessoa ou grupo de pessoas aplica sobre outra pessoa ou grupo. Sendo utilizado, em geral, de forma depreciativa, tem por finalidade deteriorar uma identidade através de ações sociais.

Assim, embora o termo surja inicialmente para referir-se a "sinais corporais com os quais se procurava evidenciar alguma coisa de extraordinário ou mau sobre o status moral de quem os apresentava"(p.11), o estigma acaba por manifesta-se nas interações sociais e está vinculado com preconceito e discriminação, pois "Um estigma é (...) um tipo especial de relação entre atributo e estereótipo" (Goffman, 1988, p.13). O estigma é, portanto uma situação (em muitos casos, permanente) presente na sociedade onde o indivíduo é impossibilitado de ser aceito por seus pares. Em sua obra, Goffman utiliza-se de dados providos por todos estes trabalhos e aprofunda-se na questão da organização social do cotidiano, ao longo do livro o autor analisa o estigma e a socialização do indivíduo enquanto estigmatizado, as situações com as quais defrontam-se os estigmatizados e suas reações dentro das esferas de interação sociais são ricas em detalhes, auxiliando na compreensão e elucidação de como é a vida cotidiana de um "estigmatizado".

Na vida cotidiana acaba-se por criar um modelo social do indivíduo, e ao longo de nossas interações nem sempre a imagem social do indivíduo corresponde à realidade, mas sim ao que o autor chama de identidade social virtual, em contrapartida com a identidade social real, que são atributos que servem como indicativo de quais categorias o indivíduo em questão participa. Assim, Goffman(1988) tece a noção de identidade baseando-se no que chama de "marcas de apoio à identidade" e com a soma singular dos eventos de uma vida, que estruturam e constroem sua identidade, permitindo que os atores se diferenciem uns dos outros. É exatamente esta diferenciação que permite construir a identidade social, servindo de alicerce para a história ininterrupta das vivências interativas do social. O outro tem importância fundamental enquanto construtor de identidade, pois a identidade vai formando-se pela ramificação de inúmeras determinações que regem o indivíduo.

Com relação ao estigma, o mesmo pode ser considerado um atributo que tira toda a credibilidade na vida pessoal do indivíduo, principalmente se for considerado um defeito ou falha em relação ao outro, considerado "normal". E é exatamente esse fato que respalda 
uma dicotomia entre a identidade social virtual e a identidade real, e essa discrepância se dá no momento que a sociedade restringe as oportunidades e nega ao estigmatizado a inclusão, em detrimento de um modelo de normalidade conveniente com a sociedade. Isso gera a deterioração da imagem que o indivíduo constrói para si diante da sociedade. Quanto maior for o abismo entre as duas identidades, mais evidente é o estigma, e essa diferença entre as identidades é arrasadora para a identidade social do indivíduo, que passa a assumir uma posição distante de si e da sociedade, o que o leva a tornar-se um desacreditado, sendo incapaz de aceitar sua condição. A partir do momento que o sujeito difere do padrão de semelhança presente na sociedade e não é capaz de adequar-se, este passa a não mais ter valor como pessoa, a se tornar um vazio nas relações com o outro, não mais podendo ser protagonista de ações sociais.

Quaisquer atributos positivos ou qualidades que o sujeito poderia ter são obliterados perante a identidade social estigmatizada, que exerce poder de dominar suas ações e acelera a deterioração de sua identidade social, evidenciando os defeitos e desvios e anulando tudo que poderia haver de positivo na identidade do estigmatizado, que perde a autoconfiança e é induzido a pensar que é incapaz, uma espécie de câncer na sociedade "saudável" que o cerca. Desde sempre pessoas com deficiência lidam com a manipulação de sua identidade, num primeiro momento na família, posteriormente em espaços sociais (principalmente na escola, onde os indivíduos passarão anos de suas vidas) dentro dos quais estabelece interações. No caso de deficiências há uma alienação e falta de categorização dos pensamentos pela sociedade em geral, desvinculando o lado humano da pessoa com deficiência, gerando uma situação de desigualdade constante, numa realidade na qual o portador de estigma é freqüentemente confrontado com um padrão de normalidade que, por vezes é inalcançável. Esta falta de categorização de pensamentos é geralmente condicionada pela falta de informação, perpetuando estereótipos e lugares-comuns, causando desconforto, constrangimento e insegurança no estigmatizado, que por vezes é privado de bens simbólicos e culturais que geram desigualdade social, como acesso ao trabalho ou educação. É natural que o portador de estigma seja resumido àquele estigma, dificultando enormemente a capacidade de atuação social daquele ator, que acaba impossibilitado de exercer um papel na sociedade.

Na vida cotidiana atual, emprega-se o discurso da aceitação, da inclusão, da diversidade, deve-se tolerar e respeitar o indivíduo portador de deficiência.

Pode-se compreender a identidade não apenas como realidade psicossocial ou mesmo biológica, mas som como algo relacionado às elaborações coletivas de cada sociedade através da sua história, a identidade está atrelada às regras e normas sociais, estabelecidos pelas relações de poder que permeiam nosso dia-a-dia. Na ótica de Goffman, a construção da identidade deteriorada que a deficiência, no nosso caso visual ${ }^{1}$, provoca, leva a um sentimento de inferioridade e a uma ação social reduzida deste indivíduo perante o grupo social.

\section{Blogs: um estudo sobre capital social, identidade e redes temáticas}

\footnotetext{
${ }^{1}$ Porém este raciocínio aplica-se a todos os outros tipos de estigmas.
} 
Os blogs surgem como ferramentas de fácil atualização em web sites, que baseiamse no sistema de micro-conteúdos e na atualização quase que diária dos mesmos, de um ou vários autores, permitindo, ainda, os comentários até mesmo de quem não é autor de blog. (Montardo, Passerino, 2006). Os blogs são parte de uma nova leva de ferramentas para transmissão, propagação e perpetuação de informações relevantes aos atores e do público envolvidos na construção dos mesmos, pois são pessoais e opinativos, oferecendo múltiplas opções de interação através de relatos, indicações, links e permitindo que se discuta sobre virtualmente qualquer tema sob qualquer perspectiva, gerando novos modelos culturais de interação em contrapartida aos veículos de mídia em massa, que ao invés de democratizar o saber e tornar o conhecimento público foram lentamente transformadas ferramentas de violência simbólica e dominação. Os conteúdos das postagens vão desde impressões pessoais (diários virtuais), publicações eletrônicas (revistas, zines, notícias) ou mesmo como um espaço para divulgar certas esferas culturais e promovê-las. (Recuero, 2003). Atualmente também há um nicho de blogs que se volta para distribuição de músicas, vídeos, filmes e toda a sorte de forma midiática que se possa imaginar, e em muitos casos, esse material é distribuído de maneira que infringe as leis.

Do ponto de vista do estudo da identidade social e das redes temáticas construídas em torno a uma comunidade virtual, eles permitem que se observem os mais variáveis e fluidos aspectos da interação social, por meio de posicionamentos, ideais e práticas de disseminação de outra informação que não a propagada pela mídia, para citar apenas uma parcela de uma miríade de possibilidades de observação. Todas essas variáveis, por sua vez, permitem análise da configuração e reconfiguração do ciberespaço e como o capital social e os laços sociais estabelecem-se entre os atores na própria Blogosfera ${ }^{2}$.

Os blogs podem muitas vezes funcionar como reconstrutores de uma identidade social deteriorada e fragmentada (Goffman, 1988) e ao mesmo tempo como ferramenta de autoafirmação e aceitação, como no caso das pessoas com deficiência. Essas reconstruções do eu tem sua gênese através de processos variáveis e multisignificativos, portanto devem-se levar em conta os múltiplos significados que geram e/ou reafirmam uma identidade na grande rede.

Utilizando-se da netnografia, é possível analisar os blogs, que são objetos de pesquisa com dados acessíveis e de fácil obtenção, permitindo um escope imenso na abordagem e armazenamento satisfatório da informação sem o uso de um diário de campo, por exemplo. Pode-se conduzir uma pesquisa muito mais rapidamente do que no modo tradicional de etnografar (Kozinets, 2000), podendo inclusive, direcionar a pesquisa facilmente para maior diversidade, mas isso pode tornar-se uma espada de dois gumes, visto que é bastante fácil perder o foco principal e desdobrar a pesquisa de forma insatisfatória ou indevida. $\mathrm{O}$ objetivo de nossa pesquisa é precisamente utilizar a netnografia na blogosfera na busca de redes temáticas que nos permitam mapear e estabelecer critérios para análise do capital e laços sociais estabelecidos entre pessoas com deficiência (neste caso visual) e familiares ou amigos. Tais sujeitos, ao contrário do que o senso comum imagina, utilizam-se massivamente da internet para buscar informações, procurar seus pares e estabelecer

\footnotetext{
${ }^{2}$ Termo coletivo para englobar todos os blogs, formando uma grande rede entre os atores sociais, sendo em si, mais do que a soma das postagens coletivas de todos os blogueiros; um fenômeno social
} 
contato entre eles, por vezes abraçando a luta contra a desigualdade social e exclusão e tentando adequar-se a este mundo, que assim como nossa realidade objetiva exclui os mesmos. Em particular, pretendemos compreender como o cego utiliza-se da internet, mais especificamente dos blogs, quais suas dificuldades, como lida com seu estigma na rede, que barreiras físicas e tecnológicas defrontam esses indivíduos e como enfrentam ou confrontam essa situação.

\section{Netnografia}

Tradicionalmente, a antropologia volta-se para a cultura, muitas vezes focando-se nas relações interpessoais e comunicativas (representações) desempenhadas pelos atores sociais, o que acaba por suprimir a ação dos objetos como relevantes nos modelos de construção dos fatos sociais que ocorrem na rede, e que pretendemos analisar e melhor entendermos, que são resultantes das relações sociais mediadas pelos computadores, mais especificamente, através de blogs.

A pesquisa etnográfica praticada na grande rede é chamada de netnografia, ela pode ser utilizada amplamente, em listas de discussão, chats, mIRC, e nessas redes temáticas específicas é possível aplicar análise de discurso nas mensagens trocadas pelos indivíduos. Portanto, é possível netnografar com entrevistas mediadas por programas variados, como o MSN, ou analisar narrativas contidas em blogs. Ao passo de que a etnografia é por excelência a ferramenta principal do antropólogo que pesquisa os territórios reais, pode-se afirmar que a mesma pode ser utilizada para analisar o ciberespaço, que assim como suas contrapartes "reais" são constituídas de muitas comunidades que se organizam e estruturam-se a partir de modelos que implicam a criação de normas, regras e rituais seguidos por aqueles que integram as comunidades, ou mesmo visitantes ocasionais.

A etnografia virtual é um meio de problematização assim como sua contraparte tradicional. (Mozo, 2005). Basicamente é um instrumento que problematiza as certezas e fatos tidos como dados que ilustram a construção do nosso cotidiano. No caso da netnografia, apropriando-se dos ambientes virtuais e demonstrando sentido nos procedimentos que operam nas estruturas do mundo virtual. O fazer etnográfico está vinculado ao progresso de uma forma de conhecimento sobre a cultura, com base na escolha de estruturas de significação, sendo assim, quem faz etnografia a partir desta perspectiva, age de certa forma, como um crítico literário (Geertz, 1989), pois está interpretando a cultura a partir de descrições dos fatos observados, que seria o papel da etnografia, procurando suas motivações e significados e não sendo apenas uma descrição detalhada, mas sim muito mais uma leitura interpretativa dessas teias de significados tecidas pelo homem, permitindo uma flexibilidade interpretativa, aproximando-se do que Geertz (1989) chama de descrição densa. Assim como a netnografia não busca retratar a risca e fielmente uma realidade, mas sim uma descrição que parta de um esforço do observador em perceber o ponto de vista do "nativo", permitindo uma compreensão dos fenômenos sociais envolvidos através do olhar do outro. Deste modo, tanto a etnografia tradicional quanto a netnografia dão grande importância à relação e comprometimento que o pesquisador tem com seu objeto de estudo, inclusive no aspecto reflexivo que permeia a análise que dará gênese à etnografia como resultado final. 
Podem-se apontar algumas diferenças entre a prática etnográfica e a netnográfica, como por exemplo, o fato de que as relações sociais no virtual e as comunidades que as estabelecem não são produtos de um espaço físico em si, mas de uma conexão mediada por uma máquina e que nos transporta ao dito campo virtual.

Portanto, se a questão de espaço é vista de outra forma na pesquisa do virtual, também difere na questão do tempo, pois as informações coletadas por vezes estão depositadas há algum tempo no ambiente virtual, congeladas, estáticas, assim como os informantes e seus discursos, que acabam não raramente suspensos no ambiente virtual, permitindo acesso irrestrito no âmbito espacial e temporal. E é justamente essa alteração na qual se perde o elemento geográfico espacial que nas interações cotidianas tem importância fundamental, que revela a revolução que é a internet como um artefato cultural (Hine, 2000) que permite sobrepujar de certa maneira, a questão espaço-tempo que é tão presente e regradora de nossa realidade objetiva. Nos ambientes virtuais o espaço exerce apenas presença simbólica, portanto desprovido de barreiras físicas, mas ao mesmo tempo transpassado por linhas estabelecidas cuidadosamente entre os atores sociais que interagem neste mundo artificial, permitindo que se pense em esferas de relacionamento e interação mais flexíveis e mutáveis que as suas contra-partes que circundam o não-virtual.

Na netnografia a tecnologia entra em primeiro plano e adquire uma importância fundamental nas interações entre os atores sociais, pois através dela opera-se toda uma realidade que não é percebida com os sentidos, pelo menos não da maneira como estamos acostumados a operar nossa perspectiva do real no cotidiano. Na grande rede, certas formas estéticas como as percebemos no dia a dia não têm a mesma importância, significados ou impressões geradas pela visualização de outro ator não são determinantes, pois a imersão no mar de informação e interação que é a grande rede e os discursos que nela ecoam se dá diferentemente do convívio cara a cara. Por vezes, enquanto interagimos no virtual, de nada nos servem estereótipos tecidos no cotidiano, como a vestimenta, gestos ou peculiaridades da fala, pois a idéia de espaço físico e a estética como conhecemos não podem ser concebidos no ciberespaço tão facilmente. Não há uma limitação física para os envolvidos nas interações e a identificação dos interlocutores na rede (Mozo, 2005) é por vezes breve ou impossível de se definir, pois a comunicação verbal acaba encontrando-se no mesmo patamar que as formas de comunicação não-verbais.

Claro que estamos falando de redes temáticas compostas basicamente por poucas imagens e sons, visto que nos dias atuais a inserção na web dá-se das mais variadas formas, seja com vídeos, podcasts, fotologs, audiologs, redes de relacionamento e jogos multiplayer, que constroem toda uma nova identidade na rede.

No caso das mensagens escritas em fóruns, redes de relacionamentos, listas de discussão e blogs, há uma possibilidade de construção de discurso que inexiste nas relações pessoais, que é a de construir uma narrativa ou tecer uma opinião sem que a mesma seja interrompida, permitindo também a articulação e estruturação de uma linha de raciocínio que pode ser muito mais cuidadosamente arranjada do que as palavras proferidas momentaneamente em voz alta. Todo o discurso desenvolvido em mensagens escritas possui um início, meio e fim, sem a possibilidade de interrupções sem prévio aviso, permitindo a flexibilidade das comunicações virtuais de forma prolixa e bem constituída, se os atores sociais assim desejarem. 
As limitações da netnografia dão-se justamente no âmbito estreito no qual se formam as comunidades virtuais, que são desprovidas da capacidade de prover informações detalhadas da vivência humana como ela dá-se no não-virtual. É necessário ser cauteloso e utilizar ao máximo as habilidades interpretativas e reflexivas ao aplicar a netnografia, aplicando métodos variados de pesquisa que se moldem aos mais variados contextos. No entanto, pode-se com a netnografia, analisar os discursos, identidades culturais e as mais diversas formas de relacionamentos que surgiram e proliferam-se com o advento da internet, e perceber como esses relacionamentos e interações aproximam-se ou se distanciam do mundo real. A netnografia tem como vantagem a dinâmica muito mais fluida e veloz que sua forma tradicional, permitindo uma obtenção de dados mais rápida e menos subjetiva, ainda que limite-se muitas vezes à análise de texto escrito (mas de longe a análise de texto é a única opção disponível para análise netnográfica no ciberespaço) (Kozinets, 2000).

A seguir desenvolvemos discussão de situações metodológicas presentes quando os sujeitos de pesquisa são pessoas estigmatizadas utilizando a netnografia como metodologia de pesquisa.

\section{Estigma e Ciberespaço: desafios da netnografia}

No caso particular da nossa pesquisa visamos estudar a sociabilidade3 que espaços como a blogosfera permitem na constituição de redes temáticas. Nesse sentido, redes temáticas podem ser definidas como redes sociais que se estruturam em torno de um tema específico e que se mantém restrita a ele (Montardo, Passerino, 2008).

Para o estudo das redes, utilizou-se a netnografia, como supracitado anteriormente. O desafio da aplicação do método netnográfico dá-se principalmente na busca por informantes confiáveis, pois ao mesmo tempo em que as comunicações mediadas por computadores no ciberespaço permitem flexibilidade e maior facilidade no processo de coleta de dados, também acabam por levar a fontes nem sempre confiáveis, da mesma forma como é comum encontrar informantes não regulares ou instáveis, prejudicando a linearidade e ordenamento dos dados obtidos, assim como o aproveitamento de seu potencial.

$\mathrm{Na}$ abordagem das redes temáticas dos blogs de estigmatizados (deficientes visuais), é ainda mais complexa a localização acurada dos mesmos, pois nem sempre o portador de estigma deseja revelar sua identidade, ademais na internet, onde se pode gozar de anonimato e esconder ou omitir traços indesejáveis provindos do estigma. Também há a questão de que nem todo o internauta deseja que detalhes de sua vida particular estejam na rede, e nem todo o indivíduo que navega nela almeja projetar blogs, fotologs, sites ou inserir-se em redes de relacionamento virtuais. Um cego habilidoso com o uso de programas de vocalização pode facilmente esconder seu estigma e gerar uma identidade virtual aparentemente normal, respondendo mensagens instantâneas tão rápido quanto qualquer outro indivíduo.

\footnotetext{
${ }^{3}$ Para Simmel (1983), a sociedade é a interação com outro para realizar os conteúdos materiais (individuais), e a partir da percepção de que as sociações envolvem, além dos conteúdos, a própria valorização da sociação pelos indivíduos. E as formas que resultam destes processos ganham vida própria, libertas dos conteúdos e existindo por si mesmas, constituindo a sociabilidade
} 
No caso particular da netnografia, que trabalha com espaços virtuais nos quais as identidades reais não podem ser percebidas de imediato pelo pesquisador, mas precisam ser declaradas, há um duplo dilema, pois como citado acima, há a possibilidade de vivenciar uma identidade não deteriorada pelo estigma num espaço com maior versatilidade, tornando-se uma alternativa tentadora para uma pessoa que sofreu todo o tipo de discriminação durante sua vida

Também é importante salientar que a acessibilidade digital disponível, apesar de contemplar as pessoas com deficiência com ferramentas, ainda é limitada, e programar uma página ou mesmo manter um blog pode ser uma tarefa deveras complicada para um cego.

Cabe, portanto ao pesquisador, utilizar-se de metodologias ágeis e flexíveis para que se possa acompanhar o fluxo de informação gerado pelas redes temáticas, como por exemplo, a técnica metodológica da "bola de neve" (Biernacki \& Waldorf, 1981) que consiste em um método não-probabilístico que é mais bem utilizado quando a população ou objeto de estudo é raro ou de difícil acesso, ao encontrar ao menos um indivíduo entendido (Goffman, 1988) ou mesmo um que tenha as características ideais procuradas pelo pesquisador é possível interar-se da rede de relações do indivíduo, obtendo indicações preciosas de onde investigar e com quem falar, expandindo o campo de pesquisa e permitindo a identificação de mais aspectos a serem pesquisados. Desta forma pode-se construir uma rede de informações, consultar mais indivíduos e a partir disso utilizar outras metodologias, como entrevistas, por exemplo.

A busca em organizações de apoio à população pesquisada gera resultados e abre novos caminhos, assim como seguir os links de blogroll contidos nos próprios blogs, que por vezes (mas nem sempre) indicam blogs com a mesma temática, facilitando a obtenção de mais fontes. Também é essencial contemplar a questão ética que envolve a pesquisa na rede, pois os pesquisados precisam aceitar a participação para que a mesma tenha validade e legitimidade. No caso da pesquisa em andamento foram localizados sete BLOGs ( 2 de Brasil e 5 de Portugal), além de um portal de acessibilidade digital especificamente construído por um cego, o estudo está centrado na fala portuguesa e como esses indivíduos relacionam-se entre si.

Para exemplificar alguns pontos relacionados ao estigma, trazemos a seguir um recorte da pesquisa. Pode-se ver claramente a questão de como o estigmatizado enfrenta sua condição através destes relatos ${ }^{4}$.

"Desde minhas primeiras lutas em prol de nossos interesses que quando meus colegas diziam "a sociedade nos ignora, nos vê com indiferença, nos renega" ou falavam as palavras chave: "preconceito e discriminação" eu pensava em minha experiência anterior, a de enxergar, e tudo aquilo era confirmado. Realmente, no meio ambiente em que vivia, zona de elite de uma grande cidade brasileira, o Rio de Janeiro, raramente alguém mencionava ter tido algum contato com cegos e, da mesma forma, com qualquer outra deficiência."

\footnotetext{
4 Material extraído de http://www.bengalalegal.com/sobrenos.php e escritos por Marco Antonio de Queiroz, também exposto no I congresso Virtual da Réd de Integración Especial, realizado na Argentina em 1/11/2000 a $1 / 12 / 2000$.
} 
Isso ilustra com clareza a naturalização ao descaso para com as pessoas com deficiência como algo que está inserido em nossa sociedade e como a falta de informação gera exclusão e repulsa por parte daqueles que se categorizam como normais, que continua elucidando a questão do imaginário que a sociedade tece sobre o cego: "tinha a certeza que éramos ignorados pela sociedade e algumas vezes, quando isso não acontecia, o que surgia não era o conhecimento propriamente dito a respeito de um cego, mas especulações e sentimentos incômodos."

Como boa parte dos problemas que afligem nossa sociedade, o descaso e até hostilidade para com os cegos dá-se em todos os níveis estruturais da sociedade, falta de tecnologias assistivas por vezes fazem da vida de um cego um desafio que requer fôlego e muita perseverança por parte dos atores envolvidos. Observa-se a dificuldade de acesso aos serviços mais comuns e fundamentais para organização da vida, como pode ser visto por esse outro fragmento:

"Muitas vezes ficamos tristes e rancorosos com coisas consideradas como
sendo "do século passado" como quando algum gerente de banco não nos
deixa abrir conta em sua agência, exigindo um responsável, não nós, que a
valide. Aí saímos de nosso anestesiado cotidiano de desigualdade para
penetrarmos em nossa realidade social em sua parte mais cruel, criando
frustrações grupais e particulares, retomando todas as nossas forças na
certeza da "ignorância social".

Se na realidade cotidiana os cegos confrontam-se com esse tipo de obstáculo, também não é diferente no ciberspaço, sendo necessária a utilização de várias ferramentas (por vezes difíceis de se usar) para realizar as tarefas que para os "normais" são tão simples quanto logar um nome e senha para acessar o email. Isso restringe, limita e exclui pessoas com deficiência dentro da rede, fazendo com que muitas pessoas deixem de se inserir no mundo virtual pela dificuldade confrontada no mesmo.

De fato, os cegos possuem uma deficiência limitadora, mas nós, normais, alienados na sociedade consumista e individualista somos incapazes de nos livrar deste véu que nos cobre a sensibilidade e tira uma visão mais importante do que a física, a visão humanista, como se pode ver na frase proferida por uma das protagonistas do romance Ensaio sobre a Cegueira, de Saramago. "O medo cega, disse a rapariga dos óculos escuros, São palavras certas, já éramos cegos no momento em que cegamos, o medo nos cegou, o medo nos fará continuar cegos" (1995, p. 131). Tal frase é uma analogia à nossa cegueira generalizada diante do mundo e como somos regrados por todas as estruturas de poder que regem as esferas do social.

Considerei que há um conjunto de indivíduos dos quais o estigmatizado pode esperar algum apoio: aqueles que compartilham seu estigma e, em virtude disto, são definidos e se definem como seus iguais. O segundo conjunto é composto (...) pelos "informados", ou seja, os que são normais, mas cuja situação especial levou a privar intimamente da vida secreta do indivíduo estigmatizado e a simpatizar com ela(...) (Goffman 1988, p. 37)

Portanto, da mesma forma que um portador de estigma encontra conforto e compreensão entre seus pares, pode contar com o auxílio e condescendência dos 
indivíduos informados, que estabelecem laços sociais com os estigmatizados, criando uma relação que conecta os pares entre si e gera capital social $^{5}$.

\section{Considerações Finais}

A busca por informantes neste estudo foi complicada, pois a população pesquisada nem sempre revela seu estigma e por vezes, prefere o anonimato. No Brasil a banda larga ainda é uma realidade distante para muitas pessoas, mas nos últimos anos foi sendo integrada aos poucos, lentamente aumentando a oferta, mas ainda sim deixando a desejar, se compararmos com a banda larga na Europa, EUA e Ásia, por exemplo. O acesso tampouco tem baixo custo, barrando até mesmo a população de classe média, apesar de os preços estarem proporcionalmente diminuindo ao passo de que a largura da banda vai sendo estendida e as ofertas aumentando. Este, sem dúvida, é um problema que os deficientes visuais enfrentam, pois a lentidão da transferência de informação é bastante frustrante no caso das tecnologias assistivas, como leitores de tela.

Também passam a enfrentar problemas semelhantes aos do cotidiano, pois as redes temáticas virtuais, assim como nossa realidade, são construídas através de uma perspectiva que se encaixa apenas aos indivíduos que se enquadram nas esferas consideradas "normais", que projetam a internet e toda sua estrutura, como os softwares operantes, navegadores e demais ferramentas utilizadas na rede.

O maior problema confrontado ao usar-se a netnografia na blogosfera definitivamente advém do fato de que ao contrário de ambientes dotados de interatividade mais fluida, como chats, mIRC, MSN e listas de discussão, os blogs costumam ser mais estáticos, sendo a única forma de interatividade dentro deles os comentários, que no caso dos blogs mantidos por cegos costumam ser esparsos, devido ao modelo de weblog (diário virtual), que vêm perdendo espaço para outros formatos de blogs (que contém notícias ou dowloads, por exemplo), mas que são muito ricos em impressões e modos de pensar dessas pessoas que expõe seu estigma na rede e procuram um espaço para dialogar entre seus pares e demais atores conectados através da rede. E é exatamente essa realidade micro dentro do todo que permite a utilização dos aspectos tradicionais da etnografia, que procura entender o "nativo" e sua condição de forma reflexiva e interpretativa.

Desta forma o progresso tecnológico trazido pelo computador ao mesmo tempo em que abre portas e gera possibilidades, também pode fazer às vezes de obstáculo, sendo que as novas interfaces que surgem acabam por dificultar o manuseio de um computador por um cego. Se a acessibilidade não progredir e for inserida ao mesmo passo que as novas tecnologias avançam, apenas se dificultará o uso dos computadores por pessoas com deficiência, e, além disso, se corre o risco de excluirmos essas pessoas, contribuindo para a formação e construção de um falso paternalismo, que ao invés de auxiliar e integrar, apenas reduz o individuo, limitando suas possibilidades de agir por conta própria e ser independente.

\section{Referências}

\footnotetext{
${ }^{5}$ O capital Social, na ótica de Pierre Bourdieu (1972), seriam relações sociais que invariavelmente são convertidas em recursos de dominação pelos atores e que indicam aquilo que podemos chamar de honra e prestígio, que por muitas vezes são negados aos estigmatizados pelos ditos "normais".
} 


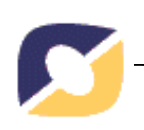

BENKENSTEIN, Arnoldo MONTARDO, S. P.; PASSERINO, Liliana. Análise das Redes Sociais em Blogs de Pessoas com Necessidades Especiais (PNE). In: Revista Novas Tecnologias na Educação (RENOTE). Porto Alegre: UFRGS, Vol. 5, no. 2, Dez. 2007.

BIERNACKI, P; WALDORF, D. Snowball Sampling: problems and techniques of chain referral sampling. Sociological Methods \& Research, vol.10 nr.2. 1981.

GEERTZ, C. 1989. A interpretação das culturas. Rio de Janeiro, Guanabara Ed.

GOFFMAN E. Estigma: notas sobre a manipulação da identidade. $4^{a}$ ed. Rio de Janeiro: LTC; 1988. A Representação do Eu na vida cotidiana. Petrópolis, Editora Vozes, 1999.

HINE, C.. Virtual Methods and the Sociology of Cyber-Social-Scientific Knowledge. In: HINE, Christine (Org.).Virtual Methods. Issues in Social Research on the Internet. Oxford: Berg, 2005.

KOZINETS, R. On Netnography: Inicial Reflections on Consumer Research InvestigationsofCyberculture.(1997)

MONTARDO, S. P.; PASSERINO, Liliana. Espelhos quebrados no ciberespaço implicações de redes temáticas em blogs na Análise de Redes Sociais (ARS). In: 17o. Encontro Nacional dos Programas de Pós-Graduação em Comunicação, 2008, São Paulo. 17o. Encontro da Associação Nacional dos Programas de Pós-Graduação em Comunicação. São Paulo : UNIP, 2008

MONTARDO, S. P.; PASSERINO, Liliana. Estudo dos blogs a partir da netnografia: possibilidades e limitações. In: Revista Novas Tecnologias na Educação (Renote). Porto Alegre: UFRGS, Vol. 4, no. 2, Dez. 2006.

MOZO, ANA. Sociabilidad en pantalla. Un estudio de la interacción en los entornos virtuales. AIBR: Revista de Antropología Iberoamericana, ISSN 1578-9705, Nº. 1,

RECUERO, R. Comunidades virtuais em redes sociais: uma proposta de estudo In: ECompós, Brasilia, Compós, v.4, Dez 2005. (2005).

SARAMAGO J. Ensaio Sobre a Cegueira, 1995, Ed. Caminho (p. 131)

SIMMEL, Georg (1983). Sociologia. São Paulo: Ática Editora. 